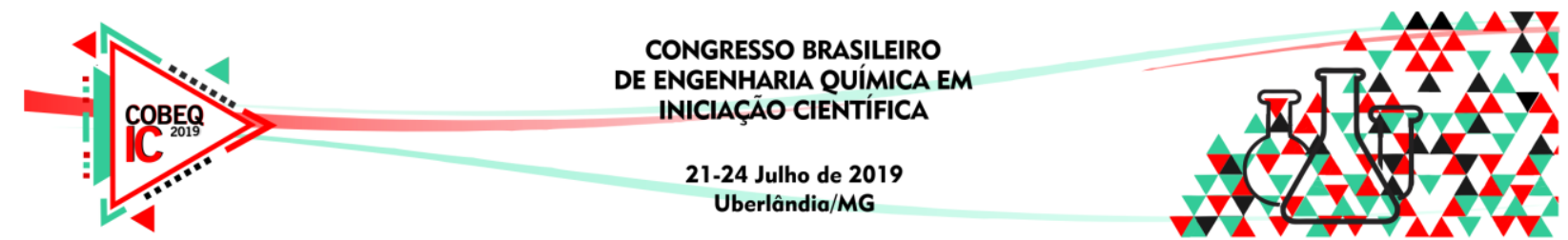

\title{
TRATAMENTO DE SUPERFÍCIES DE ALUMÍNIO COM ÁCIDO FOSFÓRICO VISANDO A OBTENÇÃO DE REFINAMENTO E BRILHO SUPERFICIAL
}

\author{
G. P. SILVA ${ }^{1}$, L. F. SILVA FILHO ${ }^{1}$, K. R. A. MELO ${ }^{1}$, C. M. PALACIO ${ }^{1}$. \\ ${ }^{1}$ Universidade Federal Rural do Semi-Árido, Departamento de Engenharia e Tecnologia, \\ Campus Mossoró, E-mail para contato: karla_rafaelaam@hotmail.com
}

\begin{abstract}
RESUMO - Por ser um material versátil, o alumínio é utilizado em grande escala em inúmeras aplicações na indústria mecânica, farmacêutica e química, entre outras. Assim, faz-se necessário o desenvolvimento de diversas formas de tratamento de superfície em função da aplicação requerida. Neste trabalho buscouse desenvolver um tratamento de superfícies de alumínio (99,5\% Al; 0,25\% Si; $0,4 \% \mathrm{Fe}$, traços) em solução de ácido fosfórico objetivando a obtenção de refinamento e brilho superficial. Como corpos de prova foram utilizadas placas com $0,7 \mathrm{~mm}$ de espessura, em formato quadrado e com área geométrica aproximada de $9,0 \mathrm{~cm}^{2}$. Os corpos de prova foram a expostas a soluções de ácido fosfórico em concentrações de $100 \%, 75 \%, 50 \%$ e $25 \%$ (v/v) (tomando a referência como $100 \%$ o ácido P.A.). O tempo de imersão e a temperatura das soluções foram as variáveis avaliadas. Utilizando-se como parâmetros a perda de massa, a análise visual do brilho e outras ocorrências, como ataque preferencial, manchas e formação de material pulverulento. Visualmente, os corpos de prova que exibiram maior brilho (praticamente espelhados) e superfícies mais homogêneas, foram os submetidos a imersão a $75{ }^{\circ} \mathrm{C}$ em soluções com concentrações equivalentes a $100 \%$ e $75 \%$. Resultados similares também foram obtidos a $75^{\circ} \mathrm{C}$ e $100{ }^{\circ} \mathrm{C}$ nas soluções com concentrações equivalentes a $50 \%$ e $25 \%$. Verificou-se ainda que o aumento do tempo de imersão à temperatura ambiente promove uma pequena melhoria em relação ao brilho e aspecto da superfície de alumínio.
\end{abstract}

\section{INTRODUÇÃO}

Segundo Soares (2017) e Meneghesso (2006) o polidor químico de alumínio, ou comumente conhecido como banho de abrilhantamento, é um processo pelo qual o alumínio é submetido à imersão em solução ácida quente. O objetivo é eliminar defeitos e gerar uma superfície brilhante com um acabamento espelhado. Tal procedimento se baseia em um mecanismo de ataque a projeções ou microscópicas montanhas (relevos, linhas de extrusão) tão rápido quanto ao que faz depressões (baixo relevo).

De acordo com Skubal e Walters (2013) existem vários métodos empregados no polimento químico do alumínio. Grande parte desses métodos consiste em utilizar uma solução ácida para remover a parte superior atômica das camadas de alumínio e promover acabamentos brilhantes e uniformes. A maioria dos métodos utiliza o ácido nítrico e/ou ácido 


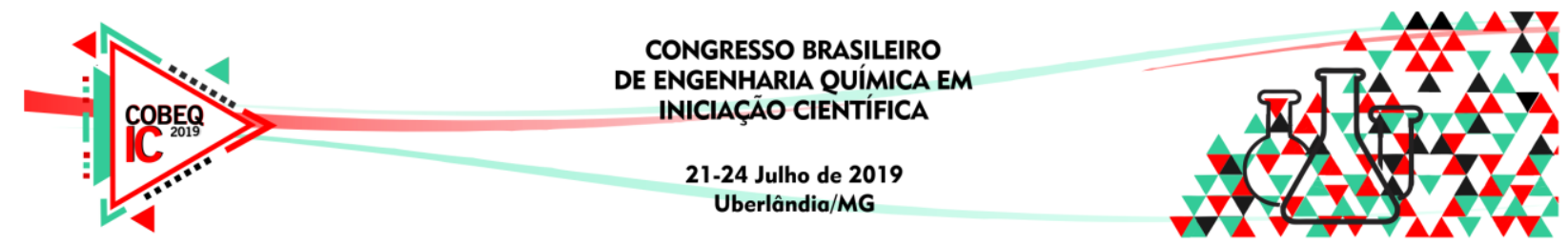

fosfórico, para minimizar a rugosidade superficial, remover riscos, manchas e marcas de polimento mecânico. $\mathrm{O}$ ácido fosfórico ataca vigorosamente o alumínio. A adição de ácido nítrico ao meio permite regular a taxa de ataque do ácido fosfórico, ou seja, a dissolução de alumínio no meio. Em geral, o ácido nítrico em excesso produz aumento da porosidade podendo inclusive ocasionar perfurações. Adicionalmente quando presente em quantidades moderadas o ácido nítrico pode produzir gravuras.

Skubal e Walters (2013) relatam que durante o processo de polimento químico a deposição de cobre proveniente da solubilização de parte da liga de alumínio é muitas vezes esperada. Um filme sólido superficial produzido com a consequente supressão da gravura e desenvolvimento do brilho. Assim, a concentração de ácido nítrico deve ser estudada na solução de polimento químico, devido a influência na deposição de partículas de cobre. Uma concentração adequada de ácido nítrico poderá permitir a distribuição partículas de cobre uniformemente.

Soares (2017) em seus estudos sobre o desenvolvimento de formulações para polimento químico de superfícies de alumínio demonstrou a importância de tal conhecimento, em função da imensa aplicabilidade do alumínio em todos os setores da indústria. A despeito da ampla utilização da técnica industrialmente, e da importância do alumínio como um dos principais materiais da construção mecânica, existem poucas publicações e referências atuais sobre este tema na literatura. Neste contexto, este trabalho visa contribuir para o desenvolvimento e aperfeiçoamento do processo de polimento químico de alumínio em meio ácido. Tendo como objetivo melhorar a qualidade da superfície em relação ao brilho e sensibilidade a manchas de impressões digitais por manuseio.

\section{METODOLOGIA}

O procedimento experimental do presente trabalho foi realizado no Laboratório de Química Aplicada da Universidade Federal Rural do Semi-Árido - UFERSA.

\subsection{Matéria prima}

Foram utilizados como corpos de prova placas de alumínio 1050 ABNT/ASTM $(99,5 \% \mathrm{Al} ; 0,25 \% \mathrm{Si} ; 0,4 \% \mathrm{Fe}$, traços), com $0,7 \mathrm{~mm}$ de espessura, nas dimensões aproximadas de 3,0 por 3,0 cm. Água destilada, Ácido Fosfórico - $\mathrm{H}_{3} \mathrm{PO}_{4}$ P.A (85\%) e Solução desengraxante industrial à $2,5 \%$.

\subsection{Equipamentos}

Os equipamentos usados nos procedimentos de polimento químico foram: vidrarias (béqueres, provetas, garras de plástico, termômetros de vidro (Promo Lab. www.allafrance.com), secador Turbo 6000 (TAIFF), chapa aquecedora (Lucadema Científica. www.lucadema.com.br), balança analítica (Tecnal Equipamentos para Laboratórios. São Paulo - SP), cronometro e câmera fotográfica.

\subsection{Preparo das soluções}




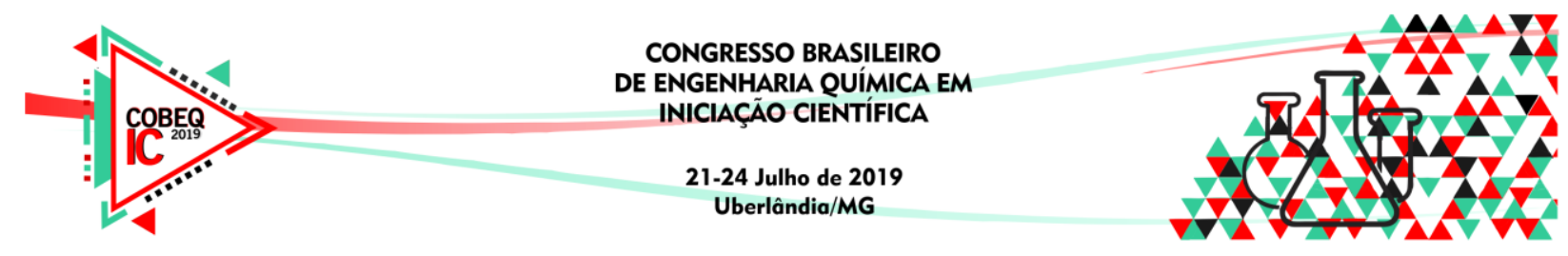

Solução desengraxante: Conforme procedimento descrito por Skoog et al. (2013), inicialmente pesou-se 2,5 g de desengraxante industrial DI-MERSAO 020-NOVA da Dileta química®. Em seguida o material foi diluído em $100 \mathrm{ml}$ de água destilada. Esta solução tem a finalidade de promover a limpeza prévia (desengordurar) das chapas de alumínio sem que estas sofram ataque químico. A concentração utilizada garante a não ocorrência de manchas provenientes da reação do desengraxante com a superfície de alumínio, recorrente em concentrações elevadas.

Soluções de ácido fosfórico: Para preparação das soluções de ácido fosfórico utilizou-se a Equação 1, também empregada em Skoog et al. (2013). Os dois termos à esquerda da equação são o volume $\left(\mathrm{V}_{\text {conc }}\right)$ e a concentração $\left(\mathrm{C}_{\text {conc }}\right)$ do ácido fosfórico concentrado, usado para preparar uma solução diluída de volume $\left(\mathrm{V}_{\mathrm{dil}}\right)$ e concentração $\left(\mathrm{C}_{\mathrm{dil}}\right)$. Essa relação tem como base a igualdade entre o número de mols do soluto existente na solução diluída que deve ser igual a número de mols no reagente concentrado. $\mathrm{O}$ volume pode ser aferido em mililitros ou litros desde que as unidades sejam as mesmas para ambas as soluções.

$$
V_{\text {cone }} \times C_{\text {cone }}=V_{\text {dil }} \times C_{\text {dil }}
$$

A concentração e o volume das soluções empregadas nos testes são apresentadas na Tabela 1. As proporções utilizadas seguem o teor comercializado para o ácido fosfórico. No caso, o ácido com teor de $85 \%$ foi denominado nesse trabalho como concentração equivalente a $100 \%$.

Tabela 1: - Concentração e o volume das soluções empregadas nos testes.

\begin{tabular}{|c|c|c|c|c|}
\hline Solução & Percentual (\%) & Equivalente (\%) & $\mathrm{H}_{3} \mathrm{PO}_{4}(\mathrm{ml})$ & $\mathrm{H}_{2} \mathrm{O}(\mathrm{ml})$ \\
\hline \hline 1 & 85,0 & 100,0 & 50,0 & - \\
\hline 2 & 63,8 & 75,0 & 37,5 & 12,5 \\
\hline 3 & 42,5 & 50,0 & 25,0 & 25,5 \\
\hline 4 & 21,3 & 25,0 & 12,5 & 37,5 \\
\hline
\end{tabular}

\subsection{Polimento químico} Figura 1:

Os procedimentos foram realizados em duplicata seguindo a sequência de mostrada na

Figura 1 - Cronograma do procedimento realizado em laboratório.

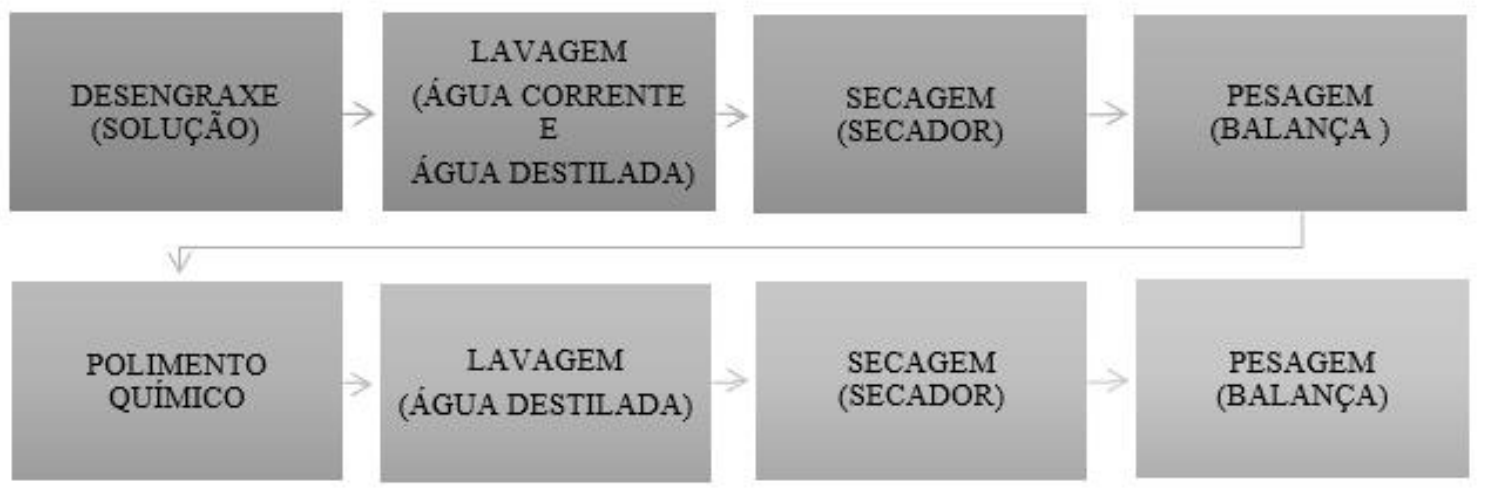




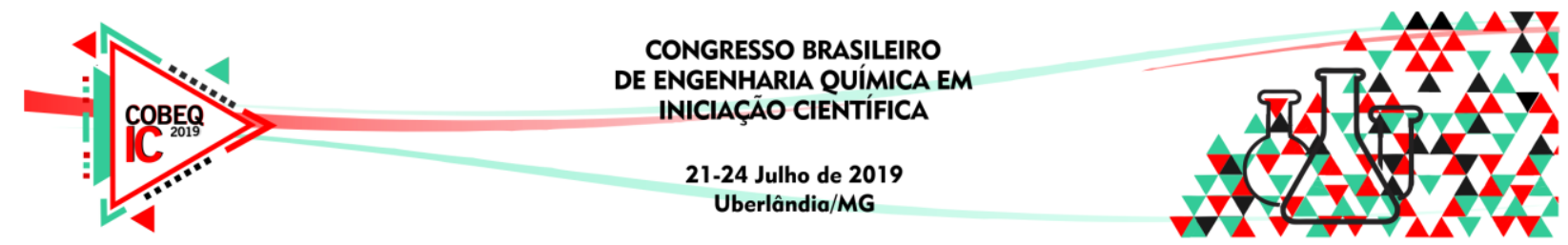

O desengraxe dos corpos de prova foram feitos por imersão durante 1,0 minuto. Na etapa de polimento químico, os corpos de prova foram imersos nas soluções de ácido fosfórico à temperatura ambiente (aproximadamente $25^{\circ} \mathrm{C}$ ) por 5,0; 10,0 e 15,0 minutos. Nos ensaios realizados nas temperaturas de $50^{\circ} \mathrm{C}, 75^{\circ} \mathrm{C}$ e $100^{\circ} \mathrm{C}$ o tempo de imersão foi de 5 minutos, para evitar ataques muito pronunciados e destruição dos corpos de prova. As identificações dos corpos de prova foram feitas conforme a solução de imersão utilizada, ou seja, 1a e 1b correspondem a imersão na solução com concentração equivalente a 100\%, 2a e 2 b a $75 \%$; 3 a e 3 b a $50 \%$; e 4 a e 4 b a $25 \%$.

\section{RESULTADOS} ácidas.

A Figura 2 mostra a perda de massa em função do tempo de imersão nas soluções Figura 2 - Perda de massa com o tempo.

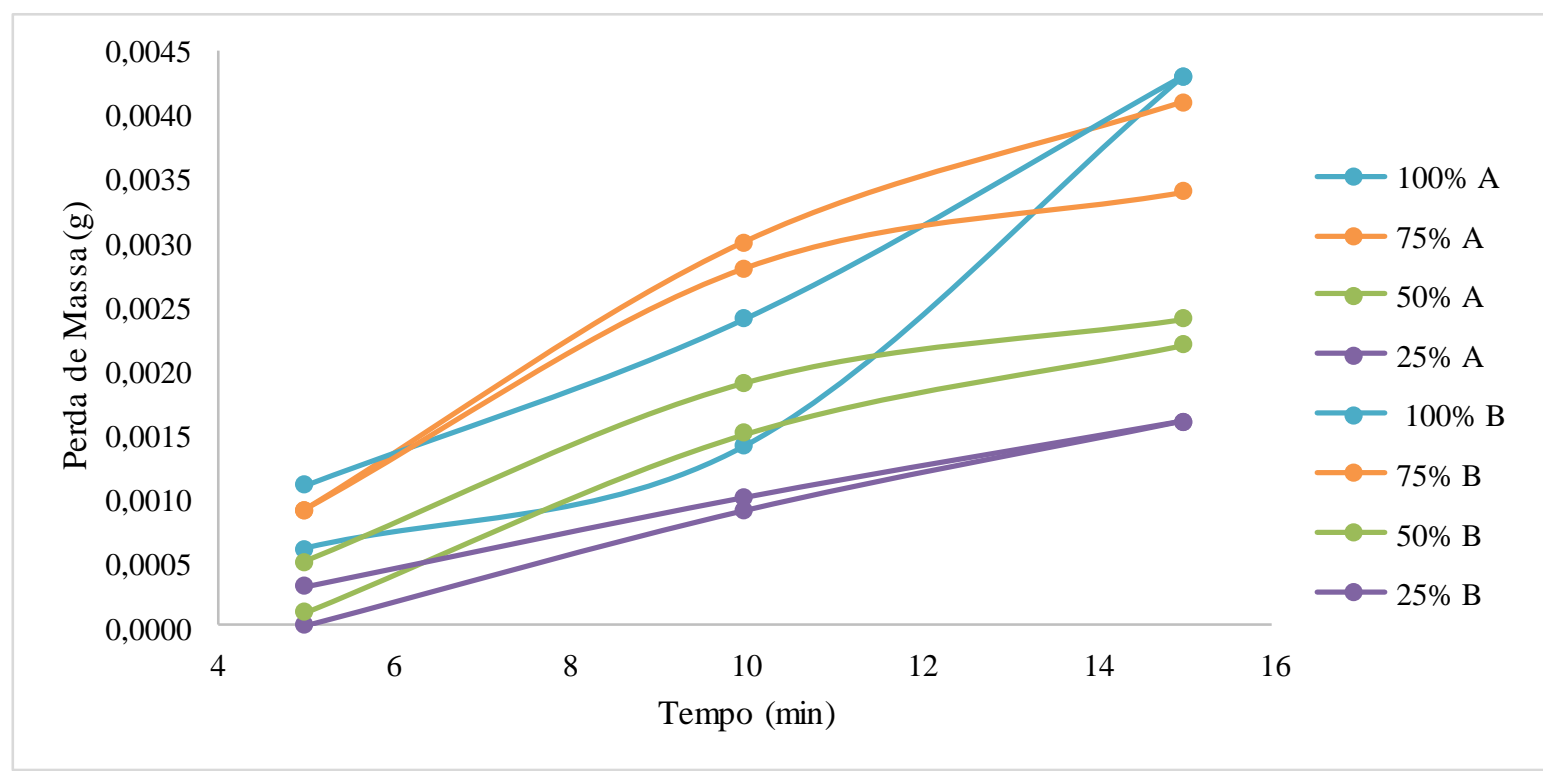

Na Figura 2, pode-se notar que para duas placas semelhantes (A e B) a perda de massa aumenta com o tempo de imersão nas soluções ácidas, esse aumento ocorre também na medida que aumenta a concentração das soluções de imersão. Fato este, decorrente da reação entre a superfície do metal e a solução em estudo. O brilho obtido no polimento é decorrente do aumento do nível de equilíbrio de $\mathrm{AlPO}_{4}$ e $\mathrm{H}_{2} \mathrm{O}$ nessa reação. Segundo Soares (2017), para que o polimento químico tenha uma boa qualidade, é necessário o controle de algumas variáveis como composição, temperatura e tempo de imersão. A variável de operação que pode ser uma das três variáveis em análise, poderá ser alterada com o objetivo de controlar o nível de equilíbrio dos componentes $\mathrm{AlPO}_{4}, \mathrm{H}_{2} \mathrm{O}$ e $\mathrm{H}_{3} \mathrm{PO}_{4}$. Tal variável pode afetar o nível de equilíbrio destes componentes na reação e a sua direção, ou seja, se seu nível de equilíbrio na reação irá aumentar ou diminuir. Como consequência desse aumento ou diminuição ocorre a formação do brilho.

A Figura 3 mostra a perda de massa em função da temperatura das soluções ácidas. 


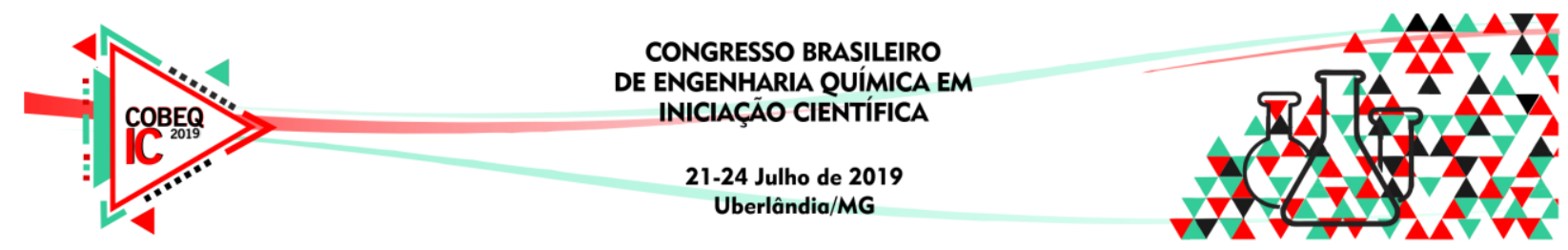

Figura 3 - Perda de massa com a temperatura.

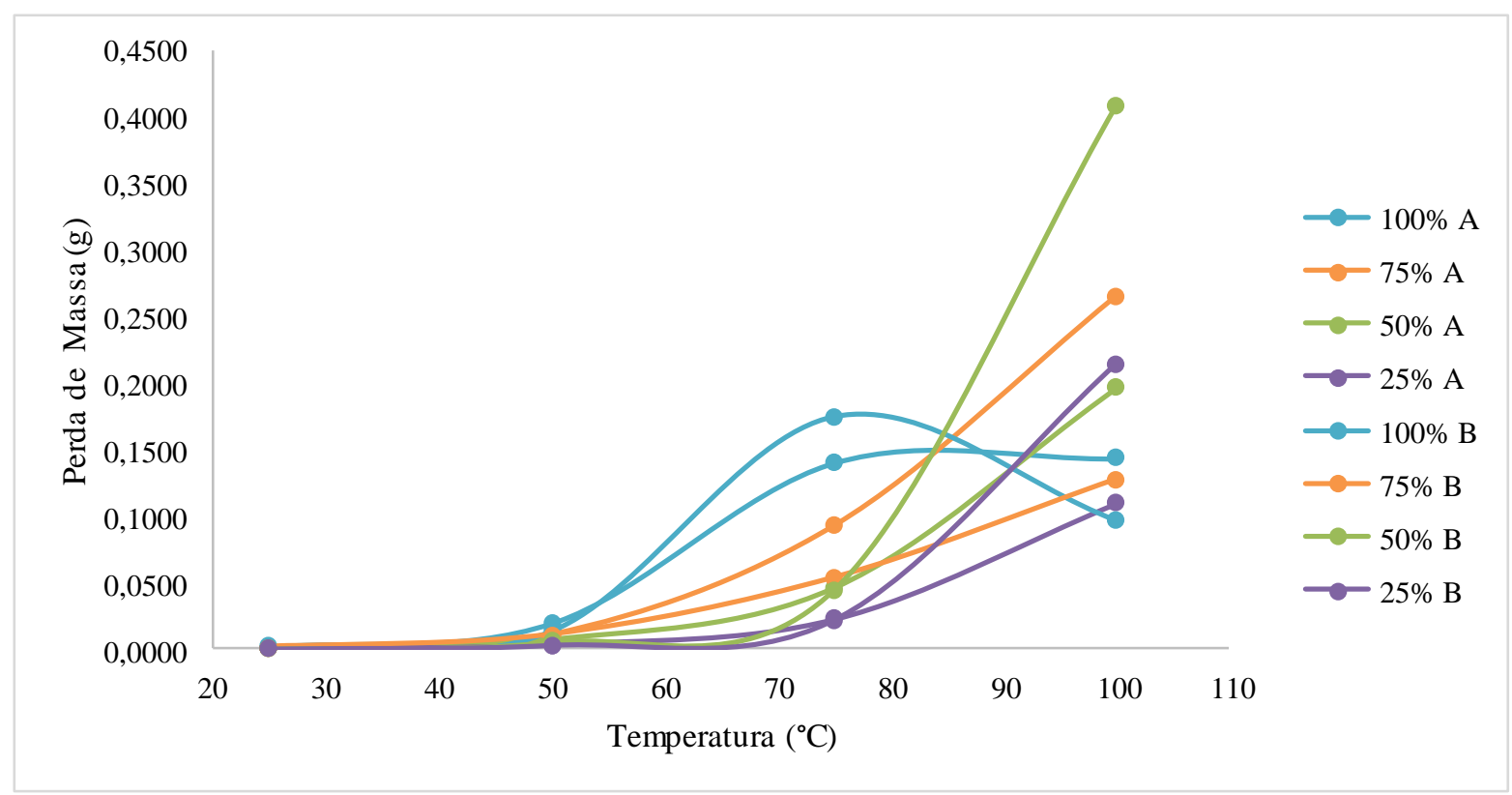

A Figura 3, mostra que a perda de massa do material em análise aumenta com o aumento da temperatura da solução de imersão. Isso se deve ao aumento da velocidade da reação, promovendo um ataque mais rápido ao alumínio. Nesse caso, o brilho obtido no polimento possivelmente é decorrente do aumento do nível de equilíbrio de $\mathrm{AlPO}_{4}$ e uma redução no nível de equilíbrio de $\mathrm{H}_{2} \mathrm{O}$ decorrente desta reação. De acordo com Soares (2017), a temperatura da solução e o tempo de imersão também podem ser usados para reduzir o nível de $\mathrm{AlPO}_{4}$ na solução. Ou seja, quando a solução de imersão atinge seu limite de $\mathrm{AlPO}_{4}$ (nível recomendado de $10-12 \% \mathrm{AlPO}_{4}$ ) em relação a qualidade. São feitos reajustes na variável de operação (variável em análise) para melhorar a qualidade em relação ao aspecto da placa. Problemas suplementares também ocorrem quando há um aumento adicional de $\mathrm{AlPO}_{4}$.

A melhor condição de uniformidade e brilho foi obtida com os corpos de prova em solução a $75^{\circ} \mathrm{C}$ com um tempo de imersão de 5,0 minutos. A Figura 4 mostra a imagem dos corpos de prova antes a após serem submetido o polimento químico.

Figura 4 - Fotografias das chapas antes (esquerda) e após (direita) a etapa de polimento na temperatura de $75{ }^{\circ} \mathrm{C}$ em um tempo de imersão de 5,0 minutos.

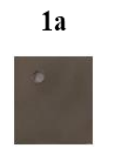

$1 b$

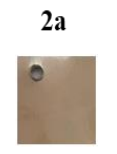

$2 b$

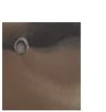

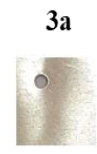

3b

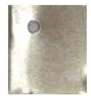

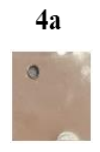

4b

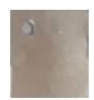

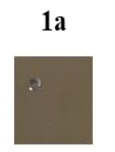

$1 \mathrm{~b}$

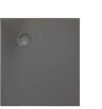

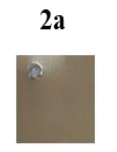

2b

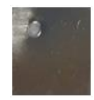

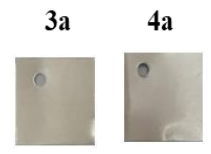

$3 b$

$4 b$
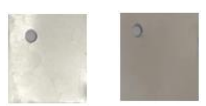

Visualmente verificou-se uma mudança mais acentuada em relação à uniformidade e ao brilho com o aumento da temperatura, atingindo um aspecto quase espelhado a $75^{\circ} \mathrm{C}$. A 


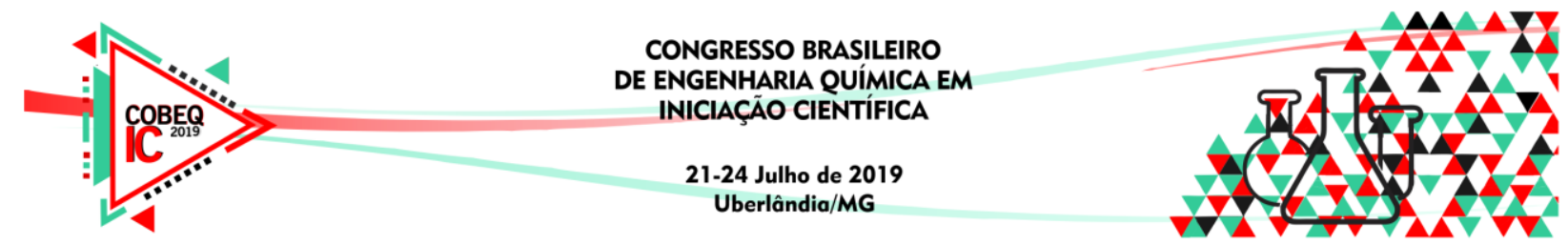

literatura relata que estes níveis de brilho geralmente são associados ao aumento do nível de equilíbrio de $\mathrm{AlPO}_{4}$, e uma redução no nível de equilíbrio de $\mathrm{H}_{2} \mathrm{O}$ na reação, conforme citado anteriormente. De acordo com Gentil (2012), quando o alumínio reage com íons $\mathrm{H}^{+}$contidos na solução ácida, ocorre o consumo de tais íons de forma que a superfície do material metálico eleva seu pH, ocasionando assim, a formação de $\mathrm{Al}\left(\mathrm{H}_{2} \mathrm{PO}_{4}\right)_{2}$ solúvel, para que então, quando o $\mathrm{pH}$ estiver entre $4-5$, formar partículas de $\mathrm{AlHPO}_{4}$ insolúvel, estas se deposita na superfície do metal em forma de cristais.

\section{CONSIDERAÇÕES FINAIS}

A perda de massa do alumínio aumenta com o aumento das variáveis tempo de imersão em solução ácida, a temperatura e a concentração da solução.

Em relação ao aumento do tempo de imersão, a reação proporciona uma mudança superficial sutil e uma pequena melhoria no brilho e uniformidade.

O aumento da temperatura promove o brilho e homogeneidade de forma mais rápida. Porém, pode ocasionar um demasiado ataque ao alumínio se esta não for bem controlada, o que acaba por manchar sua superfície e ofuscar seu brilho.

A concentração da solução de imersão também é um fator relevante. Em relação ao aspecto e brilho, para soluções com concentrações equivalentes a $25 \%$ e $50 \%$ à temperatura de $100{ }^{\circ} \mathrm{C}$ obteve-se bons resultados, de modo semelhante à temperatura de $75{ }^{\circ} \mathrm{C}$ nessas mesmas concentrações. Já na solução equivalente a $75 \%$ e $100 \%$ na temperatura de $75^{\circ} \mathrm{C}$, o aspecto observado é extremamente liso e com brilho aproximadamente espelhado.

\section{REFERÊNCIAS}

GENTIL, V. Corrosão. 6. ed. Rio de Janeiro: LTC - Livros Técnicos e Científicos. 2012. 360 p. ISBN 9788521618041.

MENEGHESSO, A. A.. Alumínio: tipos de acabamento. $C \& P$, Brasil, p.32-33, Agosto de 2006.

SKOOG, DOUGLAS A.; WEST, DONALD M.; HOLLER, F. JAMES; CROUCH, STANLEY R.. Fundamentos de Química Analítica. Tradução da $8^{\circ}$ edição norteamericana. São Paulo: Cengage Learning, 2013. 999 p.

SKUBAL D. R.; WALTERS, L. R.. Chemical polishing of aluminum coupons in support of vacuum chambers. Vacuum: Rapid Communication in Vacum, Plasma, Surface and Materiais Science. Estados Unidos, 4 de março de 2013. p. 1-6.

SOARES, P. R. O.. COMO ANODIZAR OU PINTAR ALUMÍNIO COM QUALIDADE: Abrilhantamento Químico do Alumínio. 2017. Disponível em: $<$ https://anodizarpintaraluminio.blogspot.com/2017/06/abrilhantamento-quimico-doaluminio.html>. Acesso em: 12 de novembro de 2018. 